on its care of a child with a hopeless prognosis as on its success with the survivors.

The feasibility and desirability of treatment of a grossly handicapped infant, especially in the neonatal period, is one of the most difficult decisions in paediatrics. Many factors are involved and the varying attitudes of individual surgeons and physicians and the pressures from parents accentuate the difficulties. For centuries the mainstream of medical opinion has abhorred the extremes and has trod the middle path. This was expressed in classical form by the nineteenth century English poet Arthur Clough (1819-61):

Thou shalt not kill; but need'st not strive Officiously to keep alive.

This attitude has been re-enforced by a letter written by Cardinal Jean Villot (1970), Vatican Secretary of State, to the International Federation of Catholic Medical Associations. After stressing the sacred character of life that forbids a doctor to kill and that imposes on him the duty to use all the resources of his profession to fight against death, the Cardinal writes: "But for all that, a medical man does not have to use all the techniques of survival offered by a constantly creative science."

There will always be differences of opinion between individual physicians and surgeons whether in a particular child active treatment is justified or not, but we believe that complete rejection and complete acceptance for treatment in spina bifida are both untenable-the former denies active treatment where the prognosis and the results of treatment are good and gives the survivors less than an optimum future; the latter keeps alive grossly handicapped children. Reasonably reliable objective criteria are now available for selection for treatment - their application has a marked effect on the quality of survival.

We wish to record our thanks to the following members of the spina bifida team who have worked with us in the clinic since 1961; Mr. R. S. Hooper, neurosurgeon, and his staff; Mr. P. F. Williams and Mr. M. B. Menelaus, orthopaedic surgeons; Dr. E. Wann, psychiatrist; Miss Ruth Magnus, assistant urologist; and a number of medical social workers, appliance sisters, and paramedical staff. All have contributed in various ways and have given freely of their knowledge and experience. The teachers in the preschool centres and special schools for the physically handicapped and, not least, the parents of the children have also provided essential information. To all we are greatly indebted.

\section{References}

Hagburg, B., and Sjorgen, I. (1966). American fournal of Diseases of Children,

Hide, D. W., Williams, H. P., and Ellis, H. L. (1972). Developmental Medicine and Child Neurology, 14, 304.

Ingram, T. T. S., and Naughton, J. A. (1962). Developmental Medicine and Child Neurology, 4, 287.

Laurence, K. M., and Coates, S. (1962). Archives of Disease in Childhood, 37, 345 .

Lorber, J. (1971). Developmental Medicine and Child Neurology, 13, 279.

Lorber, J. (1972). Archives of Disease in Childhood, 47, 854.

Matson, D. D. (1969). Neurosurgery of Infancy and Childhood, 2nd edn., p. 36. Springfield, Ill., Thomas.

Sharrard, W. J. W., Zachary, R. B., Lorber, J., and Bruce, A. M. (1963). Archives of Disease in Childhood, 38, 18.

Smith, E. D. (1965). Spina Bifida and the Total Care of Spinal Myelomeningocele, p. 75. Springfield, Ill., Thomas.

Smith, E. D. (1972). Fournal of Pediatric Surgery, 7, 1.

Villot, Cardinal Jean (1970). L'Ossevatore Romano, Oct. 12-13.

\title{
Predictive Factors in Open Myelomeningocele with Special Reference to Sensory Level
}

\author{
GILLIAN HUNT，WALPOLE LEWIN，JOHN GLEAVE， DOUGLAS GAIRDNER
}

British Medical fournal, 1973, 4, 197-201

\section{Summary}

A total of 113 cases of open myelomeningocele operated on shortly after birth were followed up and the 80 survivors $(71 \%)$ were assessed one and a quarter to seven and a half years later. Their disability was classified in terms of mobility, intelligence, continence, and major complications; these when combined provided an assessment of overall disability. The overall disability of the survivors was minimal in $6 \%$, moderate in $40 \%$, severe in $39 \%$, and very severe in $15 \%$.

A number of clinical features present at birth were analysed for their predictive value. Of these the sensory level, which frequently differed from both external and radiological levels of the lesion, correlated with the outcome in terms of mobility, intelligence, continence, major complications, and overall disability; and also with deaths caused by renal failure.

Addenbrooke's Hospital, Cambridge CB2 $2 Q Q$

GILLIAN HUNT, M.B., D.C.H., Research Assistant

WALPOLE LEWIN, M.S., F.R.C.S., Neurological Surgeon

WALPOLE LEWIN, M.S., F.R.C.S., Neurological

JOHN GLEAVE, F.R.C.S., Neurological Surgeon
A policy of confining operation to those patients with a reasonable chance of achieving independence would involve selecting for treatment a minority of all infants born with open myelomeningocele.

\section{Introduction}

In the past few years there has been a change in the climate of opinion, away from routine operative treatment in all cases of myelomeningocele (Lorber 1971, 1972). At the same time it has been confirmed that the most severe cases, if not operated on, rarely survive for long-some $90 \%$ dying before the end of the first year (Hide et al., 1972; Smith and Smith, 1973; Stark and Drummond, 1973). A policy of selection of cases for operation, therefore, seems to be indicated and attention needs to be directed towards criteria by which cases likely to benefit by surgery-in the sense of achieving a reasonable degree of independence-can be more accurately identified at the time of birth or soon after.

In this paper some predictive factors are examined. The social consequences of this condition will be discussed in a separate paper.

\section{Subjects and Methods}

This survey covers 113 consecutive cases of open myelomenin- 
gocele which were operated on at Addenbrooke's Hospital between 1 July 1963 and 1 January 1971 within 48 hours of birth. It is an extension of the series described by Brocklehurst et al. (1967). Simple meningoceles and late referrals are not included.

This survey was made between March 1971 and March 1972, at which time there were 80 survivors aged 1 year 3 months to 7 years 8 months. Thirty-three children had died, 23 of these (20\% of all those operated on) before their first birthday. All of the 80 survivors were located and visited, with the exception of three who were too far away to visit and on whom medical and school reports were obtained.

At the domiciliary visit a detailed history was obtained and a physical examination was made. For the assessment of intelligence an I.Q. was obtained on all the children over 5 years old through the co-operation of the school medical service. For the children under 5 years old a developmental assessment was made at the home visit. This was based on the method used by Sheridan (1960) and Egan et al. (1969) but modified to allow for the child's physical disabilities. No attempt was made to obtain a precise score but merely to place the child in one of four categories: above average, average, below average, or severely retarded. The schools were also visited and the records of the various hospitals attended were studied.

\section{Results}

From the data on mobility, intelligence, and continence, combined with any complication the severity of which materially interfered with the child's daily life, a composite assessment of overall disability was reached for each child. This overall disability, as it affected the child's daily activities and related to prospects of future independence, seemed to us to be the most meaningful way to appraise a child with multiple handicaps. Each of the 80 children was thereby placed in one of four categories, defined as follows.

Minimal Disability (five cases).-All walked without appliances and had a normal range of intelligence. All but one were continent.

Moderate Disability (32 cases).-All could walk but none could run, some could walk only a few steps, nearly all had calipers. One-third had low intelligence but none were severely retarded.

Severe Disability (31 cases).-None could walk 20 yards (18 metres), some could not walk at all. Many had severe kyphosis. There were all grades of intelligence including five severely retarded. Only one child was continent.

Very Severe Disability (12 cases).-Ten of these could not walk at all. All but one were severely retarded. Two were totally blind, three were blind in one eye. All were incontinent.

The category of disability of the $\mathbf{8 0}$ survivors is shown in the figure.

\section{OUTCOME RELATED TO PREDICTIVE FEATURES}

Features noted at birth were now correlated with the overall disability. Data were taken from the detailed notes recorded during the original admission for closure, and generally made by a senior member of the neurosurgical staff. The assessment at follow-up was made by a single observer (G.H.). We have analysed the outcome related to six predictive features: height of sensory level; presence or absence of neural plaque, combined with sensory level and separately; motor activity of the legs in terms of quadriceps function; hydrocephalus at birth; external level of the lesion; and results of infection.

\section{Sensory Level}

The sensory level is taken as the first dermatome of normal sensation above the area of anaesthesia. Sensory testing was a routine part of the preoperative examination of every child. The technique appears at first sight to be crude but in experienced hands has proved to be remarkably accurate in the long term. The resting baby is pricked with a pin, working from the region of the lowest dermatome upwards, and the level at which general arousal occurs is noted. It is necessary to exclude spinal reflex movements which occur below the level of the lesion and some experience is required in distinguishing these from movements for which the integrity of higher pathways is necessary. In the 79 survivors* the initial assessment proved to be accurate to within two segments on the trunk and one segment in the lower limbs. It was even possible to detect asymmetrical and partial loss. The value of neurological experience in carrying out this test is of great importance, for the assessment done by the junior staff was on occasion widely out. There does seem a general tendency for the sensory level to shift one dermatome caudally over the first year to 18 months. It is impossible to be certain whether this observation indicates true neurological improvement, which could conceivably occur either by ingrowth of cutaneous nerve fibres from the segment above into the denervated area below or by restoration of root function. Over the trunk, owing to the small size of a neonate, precision to within one or two segments cannot be expected.

Three groups were defined as (a) high sensory level T5-T10, (b) intermediate sensory level T11-L3, and (c) low sensory level L4 and below. (This last group contained four children in whom no sensory loss was detected.) The overall disability in cases with low sensory level was significantly better than cases with high sensory level $(\mathrm{P}<0.001)$ (table I).

TABLE I-Overall Disability Related to Sensory Level in 79 Cases of Myelomeningocele

\begin{tabular}{|c|c|c|c|c|c|}
\hline Sensory Level & & $\underset{(\mathrm{n}=5)}{\text { Minimal }}$ & $\begin{array}{l}\text { Moderate } \\
\text { Disability } \\
(\mathbf{n}=32)\end{array}$ & $\begin{array}{c}\text { Severe } \\
\text { Disability } \\
(\mathbf{n}=\mathbf{3 0})\end{array}$ & $\begin{array}{c}\text { Very } \\
\text { Severe } \\
\text { Disability } \\
(n=12)\end{array}$ \\
\hline High $(\mathbf{n}=33)$ & $\begin{array}{r}\text { T5 } \\
6 \\
7 \\
8 \\
9 \\
9 \\
10\end{array}$ & & $\begin{array}{l}* \\
* \\
* * * * *\end{array}$ & $\begin{array}{l}* \\
* * * * * * \\
* * * * * * * \\
* *\end{array}$ & $\begin{array}{l}* * \\
* * * * \\
* *\end{array}$ \\
\hline Intermediate $(n=28)$ & $\begin{array}{r}11 \\
12 \\
\mathrm{~L}_{1} \\
2 \\
3\end{array}$ & & $\begin{array}{l}* * * * * * \\
* * * * * \\
* * *\end{array}$ & $*$ & $* * *$ \\
\hline Low $(n=18)$ & $\begin{array}{r}4 \\
5 \\
51 \\
2 \\
3 \\
4 \\
5\end{array}$ & * & $*^{*} *$ & $*$ & \\
\hline No sensory loss & 0 & $* *$ & * & * & \\
\hline
\end{tabular}

Overall disability of cases with low sensory level significantly better than cases with Overall disability of cases with
high sensory level, $\mathrm{P}<0.001$

The importance of the sensory level as a predictor has not been previously stressed because attention has been focused more on motor activity of legs and on external or the radiological $\dagger$ extent of the lesion. The upper limit of neither of these

* In two babies the sensory levels or the two sides of the body were widely different so that it was not possible to give a single index in either case. These two children ( 1 alive and 1 dead) have therefore been excluded from the analyses based on sensory levels, so that in the tables concerned with sensory level (tables I-VI) the numbers of surviving cases is 79 and deaths 32 instead of 80 and 33 respectively.

tThe radiological extent of the myelomeningocele is defined as those vertebrae in which the interpedicular distance is at least $2 \mathrm{~mm}$ greater than normal, taking into account the region of the spine, the interpedicula distance of the vertebrae above and below the lesion, and any abnormalities of the vertebral arch seen on the lateral film. In several children there were areas where the vertebrae showed increased interpedicular distance were removed from the myelomeningocele. The number of dysraphic vertebrae removed from the myelomeningocele. The number of dysraphic vertebrae between the number of dysraphic vertebrae and the final handicap. 
last two necessarily coincides with the sensory level, and the disparity in many of our cases was wide. Of the cases in this series $66 \%$ had a sensory level above the upper extent of the radiological dysraphism, the most extreme being seven dermatomes above; in $16 \%$ they coincided; in $18 \%$ the sensory level was below the upper level of the dysraphism, in one case nine dermatomes below. In most of the cases with high or extensive lesions the sensory level is above the radiological lesion; in the lower or smaller ones it is more often at or below the upper radiological limit of the lesion.

In the five cases whose disability was minimal (see fig.), and in whom the sensory levels were at L5 or below (table I), the levels of the external lesions were strikingly varied, being midthoracic in one, lumbosacral in two, and sacral in two. In all five the sensory level was below the upper limit of the radiological level.

\section{Neural Plaque}

In this series only open myeloceles are considered; there are no cases in which the back lesion was completely skin covered. The cases in this series are classified as myeloceles because all the lesions contained neural elements and in every case the cord was abnormally situated. Most of the lesions were more than $5 \mathrm{~cm}$ in length and in 59 the abnormal cord or cauda equina was presenting on the surface of the lesion as a plaque which was plainly visible before operation. In 21 cases a plaque was not so easily visible though its presence always manifested itself by some dimpling of the overlying membrane, an area of granulation, or an area of scar tissue. Where there was not an obvious plaque on the surface the outcome seemed to be more favourable, and in this group were all the five children who were finally left with minimal disability only.

\section{Quadriceps}

Cases of severe and extensive paralysis in whom there was no voluntary activity at all in the legs except possibly some hip flexion were compared with cases in whom the paralysis was

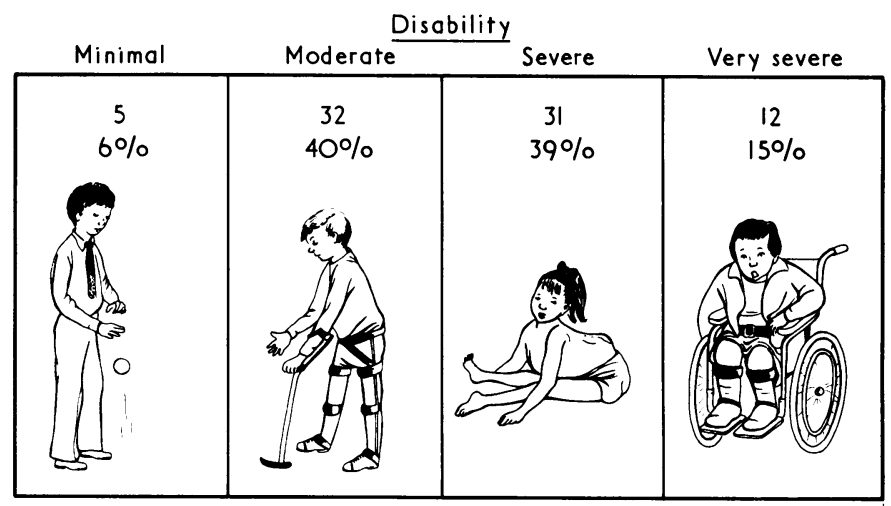

Results of treatment in 80 children with myelomeningocele.

TABLE II-Outcome Related to Predictive Features

\begin{tabular}{|c|c|c|c|c|c|c|c|c|c|c|c|c|}
\hline \multirow[b]{2}{*}{ Favourable Features } & \multicolumn{4}{|c|}{ Disability of Survivors $(\mathbf{n}=80)^{*}$} & \multirow{2}{*}{$\begin{array}{c}\text { Dead } \\
(\mathbf{n}=33)\end{array}$} & \multirow{2}{*}{ Unfavourable Features } & \multicolumn{4}{|c|}{ Disability of Survivors $(n=80)^{*}$} & \multirow{2}{*}{$-(\mathbf{n}=33)$} & \multirow{2}{*}{$\begin{array}{c}\text { Significance of } \\
\text { Difference between } \\
\text { Favourable and } \\
\text { Unfavourable } \\
\text { Features } \dagger\end{array}$} \\
\hline & $\underset{(\mathbf{n}=5)}{\text { Min. }}$ & $\begin{array}{c}\text { Mod. } \\
(\mathrm{n}=32)\end{array}$ & $\begin{array}{c}\text { Severe } \\
(\mathbf{n}=31)\end{array}$ & $\begin{array}{c}\text { Very } \\
\text { Severe } \\
(\mathrm{n}=12) \\
\end{array}$ & & & $\underset{(\mathbf{n}=5)}{\text { Min. }}$ & $\begin{array}{c}\text { Mod. } \\
(\mathrm{n}=32)\end{array}$ & $\begin{array}{c}\text { Severe } \\
(\mathbf{n}=31) \\
\end{array}$ & $\begin{array}{c}\text { Very } \\
\text { Severe } \\
(\mathbf{n}=12)\end{array}$ & & \\
\hline $\begin{array}{c}\text { Low sensory level L4 } \\
\text { below }(\mathrm{n}=18)\end{array}$ & 5 & 10 & 3 & 0 & 6 & $\begin{array}{c}\text { High sensory level T10 } \\
+ \text { above }(\mathrm{n}=33) \ldots \\
\text { Intermediate sensory } \\
\text { level T11-L3 }(\mathrm{n}=28) \\
\end{array}$ & $\begin{array}{l}0 \\
0 \\
\end{array}$ & $\begin{array}{r}7 \\
15 \\
\end{array}$ & $\begin{array}{l}17 \\
10 \\
\end{array}$ & $\begin{array}{l}9 \\
3 \\
\end{array}$ & $\begin{array}{r}17 \\
9 \\
\end{array}$ & $\begin{array}{l}P<0.001 \\
P<0.05\end{array}$ \\
\hline $\begin{array}{l}\text { No neural plaque } \\
(\mathrm{n}=21) \quad \cdots\end{array}$ & 5 & 10 & 4 & 2 & 4 & Neural plaque $(n=59)$ & 0 & 22 & 27 & 10 & 29 & $\mathrm{P}<0.01$ \\
\hline $\begin{array}{l}\text { Combined low sensory } \\
\text { level and no plaque } \\
(\mathrm{n}=9) \\
\end{array}$ & 5 & 3 & 1 & 0 & 0 & $\begin{array}{l}\text { Combined high neutral } \\
\text { level and sensory } \\
\text { plaque }(\mathbf{n}=30) \quad \cdots \\
\end{array}$ & 0 & 6 & 17 & 7 & 16 & $P<0.001$ \\
\hline $\begin{array}{l}\text { Active quadriceps } \\
(\mathbf{n}=37) \quad \cdots\end{array}$ & 5 & 18 & 12 & 2 & 16 & $\begin{array}{l}\text { Paralysed quadriceps } \\
(\mathrm{n}=43) \quad \ldots\end{array}$ & 0 & 14 & 19 & 10 & 17 & $\mathrm{P}<0.02$ \\
\hline $\begin{array}{l}\text { Head size }<90 \text { th centile } \\
\text { at birth }(\mathrm{n}=60) \quad \cdots\end{array}$ & 5 & 27 & 24 & 4 & 25 & $\begin{array}{c}\text { Head size }>90 \text { th centile } \\
\text { at birth }(\mathrm{n}=20) \quad \ldots\end{array}$ & 0 & 5 & 7 & 8 & 8 & $P<0.05$ \\
\hline $\begin{array}{ll}\text { External level: } & \\
\quad \text { Thoracic }(n=1) & \ldots \\
\text { Lumbar }(n=13) & \ldots \\
\text { Lumbosacral } & \\
(\mathrm{n}=25) & \\
\text { Sacral }(\mathrm{n}=5) & \ldots \\
\end{array}$ & $\begin{array}{l}1 \\
0 \\
2 \\
2 \\
\end{array}$ & $\begin{array}{r}0 \\
7 \\
14 \\
1 \\
\end{array}$ & $\begin{array}{l}0 \\
5 \\
8 \\
2 \\
\end{array}$ & $\begin{array}{l}0 \\
1 \\
1 \\
0\end{array}$ & $\begin{array}{l}1 \\
7 \\
5 \\
6\end{array}$ & $\begin{array}{l}\text { External level: } \\
\text { Thoracolumbar } \\
(\mathrm{n}=26) \\
\text { Thoracolumbo- } \\
\text { sacral }(\mathrm{n}=10)\end{array}$ & $\begin{array}{l}0 \\
0\end{array}$ & $\begin{array}{l}8 \\
2\end{array}$ & $\begin{array}{l}9 \\
7\end{array}$ & $\begin{array}{l}9 \\
1\end{array}$ & $\begin{array}{r}12 \\
2\end{array}$ & $P<0.01$ \\
\hline No infection $(n=73)$ & 5 & 32 & 28 & 8 & 25 & Infection $(n=7)$ & 0 & 0 & 3 & 4 & 8 & $P<0.01$ \\
\hline
\end{tabular}

*In data on sensory level 79 cases and 32 dead (two omitted on account of widely asymmetrical sensory level).

tRelative numbers of cases with minimum or moderate disability compared with numbers with severe or very severe disability.

TABLE III-Mobility, Intelligence, Continence, and Overall Disability Related to Sensory Level in 79 Children* Operated on for Myelomeningocele

\begin{tabular}{|c|c|c|c|c|c|c|c|c|c|c|c|c|c|}
\hline \multirow[b]{2}{*}{ Sensory Level } & \multicolumn{3}{|c|}{ Mobility } & \multicolumn{4}{|c|}{ Intelligence } & \multicolumn{2}{|c|}{ Continence } & \multicolumn{4}{|c|}{ Overall Disability } \\
\hline & Good & Poor & None & $\begin{array}{c}\text { Above } \\
\text { Average }\end{array}$ & Average & $\begin{array}{c}\text { Below } \\
\text { Average }\end{array}$ & $\begin{array}{l}\text { Severely } \\
\text { Retarded }\end{array}$ & Yes & No & Minimal & Moderate & Severe & $\begin{array}{l}\text { Very } \\
\text { Severe }\end{array}$ \\
\hline $\begin{array}{l}\text { High, T5-T10 }(n=33) \\
\text { Intermediate, T11-L3 }(n=28) \\
\text { Low, L4 or lower }(n=18) \dagger . .\end{array}$ & $\begin{array}{r}3 \\
14 \\
13\end{array}$ & $\begin{array}{r}21 \\
7 \\
5\end{array}$ & $\begin{array}{l}9 \\
7 \\
0\end{array}$ & $\begin{array}{l}2 \\
3 \\
5\end{array}$ & $\begin{array}{r}10 \\
6 \\
6\end{array}$ & $\begin{array}{r}10 \\
14 \\
7\end{array}$ & $\begin{array}{r}11 \\
5 \\
0\end{array}$ & $\begin{array}{l}2 \\
5 \\
6\end{array}$ & $\begin{array}{r}21 \\
19 \\
8\end{array}$ & $\begin{array}{l}\mathbf{0} \\
\mathbf{0} \\
\mathbf{5}\end{array}$ & $\begin{array}{r}7 \\
15 \\
10\end{array}$ & $\begin{array}{r}17 \\
10 \\
3\end{array}$ & $\begin{array}{l}9 \\
3 \\
0\end{array}$ \\
\hline
\end{tabular}

* One case omitted on account of widely asymmetrical sensory level.

tIncluding four children with no sensory loss. Good mobility = able to walk at least 20 yards $(18$ metres) with or without aids or in the case of young children, able to bear weight on legs; poor mobility = walking only a
few steps or having some function in legs if walking has not yet been achieved; no mobility = no useful walking and severe paraplegia.

In children over 5 years above average intelligence = I.Q. $>110$; average $=$ I.Q. 110-90; below average $=\mathrm{I}$.Q. $90-70 ;$ severely retarded $=\mathrm{I}$.Q. $<70$; for children under 5 see text.

Continence refers only to children over 3 years $(n=61)$ and implies the social rather than neurological condition. Low sensory level significantly better than high for mobility $(P<0.001)$, continence $(P<0.05)$, overall disability $(P<0.001)$. Low sensory level significantly better than com-
bined intermediate and high for intelligence $(P<0.05)$. 
confined to a lower level and in whom the quadriceps in one or both legs showed some voluntary activity. Those with active quadriceps showed less overall disability but this relation was not as well defined as that between sensory level and overall disability. Errors occurred in this series as a result of poor condition of the baby, from reflex movement, or after breech delivery. Sixteen of the 80 survivors had been delivered by breech, and it was noticeable that many of them showed better mobility when later assessed than would have been expected from examination at birth. Eventual mobility in the whole series was predicted slightly better by sensory level than by motor function at birth (the tau coefficient of rank correlation was 0.45 for sensory level and final mobility as opposed to 0.42 for movement at birth and final mobility).

\section{Hydrocephalus}

Hydrocephalus present at birth was defined as having a head circumference greater than the 90th centile using O'Neill's (1961) norms based on head circumference related to weight. The birth weights of the babies in this series range from $1,500 \mathrm{~g}$ to $4,200 \mathrm{~g}$. Children born with hydrocephalus subsequently showed a somewhat greater overall disability and a lower range of intelligence than the rest of the series. They did not, however, show any difference in mortality (table II).

\section{External Level}

Despite the good correlation between height of sensory level and overall disability (table I), that between external level and overall disability was poor. We agree with others (Lorber, 1972) that there are a higher proportion of severely handicapped cases among those presenting with thoracolumbar and thoracolumbosacral lesions than in those with thoracic, lumbar, lumbosacral, or sacral lesions. But we do not find this feature of high predictive value.

\section{Infection}

The effects of infection-meningitis, ventriculitis, and septicaemia - are added to table II despite the fact that this complication could rarely have been anticipated at birth. In our series the final results after treating these cases were uniformly bad. The onset of this complication should perhaps be a contraindication to further treatment.

\section{PREDICTIVE VALUE OF SENSORY LEVEL}

The good correlation between sensory level and overall disability $(P<0.001)$ detailed in table I led to an analysis of the three component parameters-mobility, intelligence, and continence. The results are summarized in table III which shows that mobility, intelligence, and continence were all significantly better in the low sensory level group. These results are in agreement with the findings of Smith and Smith (1973). From table III it can be seen that most of the children whose sensory level was high (T5-T10) had poor mobility, low intelligence, and were incontinent. Most were severely disabled, and there were none whose disability was minimal. By contrast, the children with a low sensory level (L4 or below) mostly had good mobility, all were of near average intelligence, and many were continent. In this group there were no severely retarded or chairbound children, no cases of severe kyphosis, and no blind or partially, blind children, and none who had suffered cold injury. All the five children with minimal disability were in this group, their sensory levels were L5 or below (two of them had no sensory loss). Three of these five children had had their hydrocephalus treated by ventriculoatrial shunt.
The incidence of hydrocephalus was significantly higher $(P<0.05)$ among cases with high sensory level than those with low sensory level. Of the cases with high sensory level $36 \%$ were born with head circumference greater than the 90 th centile compared with $2 \%$ of cases with low sensory level. Altogether 73 of the 80 survivors ( $91 \%$ ) required relief of hydrocephalus by ventriculoatrial shunt. The following complications were also significantly higher among cases with a high sensory than with a low sensory level: eye defects $(P<0.05),{ }^{*}$ kyphosis $(P<0.001)$, chilblains $(P<0.05)$, and faecal incontinence $(P<0.05)$. There was no significant correlation between height of sensory level and the incidence of ventriculitis, convulsions, $\uparrow$ urinary infections, fractures, or pressure sores.

Lorber (1972) has given certain signs apparent at birth which imply severe disability and are adverse criteria to selection for treatment-namely (1) thoracolumbar or thoracolumbosacral lesions; (2) severe paralysis; (3) kyphosis; (4) severe clinical hydrocephalus; (5) other gross congenital defects or cerebral birth injury. The first four of these correlated in our series with high and intermediate sensory level (see Appendix). They are useful parameters where sensory level is difficult to define.

The most unexpected and probably one of the most important relations found from the data was that between deaths from renal failure and sensory level. Reference to table II shows that in treated cases of myelomeningocele mortality from all causes bore little relation to initially unfavourable features, except in cases of infection or in the presence of a neural plaque. Thus many severely disabled patients continue to live while some of the best cases with low sensory level succumb. There was, however, in this series a clear correlation between deaths from renal causes and sensory level. Here again our findings are remarkably similar to Lorber's. In his series of 200 cases renal deaths occurred only in cases with adverse criteria for selection; in our series of 113 they occurred only in cases with high or intermediate sensory levels (table IV). More specifically all seven renal deaths in our series occurred in the 54 cases with a sensory level of T11 or above (significant, $\mathrm{P}<0.01$ ). Since this

TABLE IV-Renal Deaths in Lorber's (1972) Series and Present Series

\begin{tabular}{|c|c|c|c|c|c|}
\hline & & & & No. of Cases & Renal Deaths \\
\hline $\begin{array}{l}\text { Lorber's series ( } 200 \text { cases } \\
\text { With adverse criteria } \\
\text { No adverse criteria }\end{array}$ & $\because$ & $\because$ & $\because$. & $\begin{array}{r}151 \\
49 \\
\end{array}$ & $\begin{array}{r}13 \\
0\end{array}$ \\
\hline \multicolumn{3}{|c|}{$\begin{array}{l}\text { Present series (111 cases): } \\
\text { High and intermediate sensory levels } \\
\text { Low sensory levels } \ldots\end{array}$} & 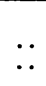 & $\begin{array}{l}87 \\
24\end{array}$ & $\begin{array}{l}7 \\
0\end{array}$ \\
\hline
\end{tabular}

review was made two more children are known to have died from renal causes and their sensory levels were T8 and T10. In patients dying from renal causes there is associated a uniformity of high sensory level despite a diversity of both external and radiological levels as shown in table V. A sensory level of T11 or above denotes an interruption in the cord above the sympathetic outflow to the kidney (T12-L1) and ureters $(\mathrm{L} 1$ + L2) (Hamilton, 1966). There is evidence that when interruption of the spinal cord occurs above or at the level of the sympathetic outflow to the legs (T11-L2) the sympathetic nerves deprived of control from higher centres give rise to abnormal and exaggerated vasomotor reflexes in the legs (Porter, 1967). In our series we found chilblains in the legs were associated with sensory levels from T6 to L3 but none occurred when the sensory level was below L3. It is tempting to speculate that similar sympathetic overaction may occur in the upper renal tract in association with cord lesions above or at the renal sympathetic outflow giving rise to abnormalities in

*Visual defects consisted chiefly of squints, but two children were totally blind. Three further children had loss of vision in one eye due to chronic corneal ulceration associated with loss of corneal sensation.

$\dagger$ Epilepsy occurred in 15 of the 73 children with ventriculoatrial shunts but in none of the seven children without shunts. 
vasomotor control or neuromuscular mechanisms in the upper renal tract. This may explain the increased renal mortality associated with cord lesions at or above T11.

TABLE v-External, Radiological, and Sensory Levels in Children Dying of Renal Causes

\begin{tabular}{|c|c|c|c|}
\hline Case No. & Cutaneous Level & Dysraphic Vertebrae & Sensory Level \\
\hline $\begin{array}{l}1 \\
2 \\
3 \\
4 \\
5 \\
6 \\
7\end{array}$ & $\begin{array}{l}\text { Thoracolumbosacral } \\
\text { Lumbosacral } \\
\text { Lumbosacral } \\
\text { Lumbosacral } \\
\text { Lumbosacral } \\
\text { Lumbosacral } \\
\text { Thoracolumbosacral }\end{array}$ & $\begin{array}{l}\text { T12 - sacrum } \\
\text { L2 } \text { sacrum } \\
\text { T4-T12, L2 - sacrum } \\
\text { L1 Z sacrum } \\
\text { L1 = sacrum } \\
\text { L1 Z sacrum } \\
\text { T7 - sacrum }\end{array}$ & $\begin{array}{l}\text { T10 } \\
\text { T10 } \\
\text { T9 } \\
\text { T11 } \\
\text { T10 } \\
\text { T10 } \\
\text { T6 }\end{array}$ \\
\hline $\begin{array}{c}\text { Died since } \\
\text { survey began: } \\
8 \\
9\end{array}$ & $\begin{array}{l}\text { Thoracolumbar } \\
\text { Thoracolumbosacral }\end{array}$ & $\begin{array}{l}\text { T1 } \\
\text { T11 - sacrum }\end{array}$ & $\begin{array}{l}\text { T8 } \\
\text { T10 }\end{array}$ \\
\hline
\end{tabular}

\section{Conclusions}

It is clear that in deciding whether or not to advise surgery no single criterion is going to suffice. The age and competence of the parents and their wishes in the matter, the number of children in the family, and the availability of specialist medical services and appropriate educational and training facilities must all play a part in the decision. But the fundamental question of the possibility of achieving a reasonable degree of independence is governed almost totally by the neurological deficit. In assessing this we wish to emphasize the importance of the sensory level.

We would like to thank the paediatricians in the East Anglian Region as well as many other paediatricians, medical officers of health, and general practitioners for their help in providing much of the information on which this report is based. We are also indebted to the many school-teachers, psychologists, and physiotherapists in the region who gave invaluable help with the disability assessments. Our thanks are due to Dr. E. C. Poulton, of the Medical Research Council, for doing the statistics, to Mrs. Sheldon for the figures, and to $\mathbf{M r}$. A. E. Holmes and Mr. A. H. G. Murley for advice in the preparation of this paper.

This research was carried out with financial support from the East Anglian Regional Hospital Board and The United Cambridge Hospitals.

APPENDIX-Lorber's (1972) Adverse Criteria Related to Sensory Level in 79 Cases

\begin{tabular}{|c|c|c|c|}
\hline \multirow[b]{2}{*}{ Adverse Criteria } & \multicolumn{3}{|c|}{ Sensory Level } \\
\hline & $\underset{(\mathbf{n}=33)}{\text { High }}$ & $\begin{array}{c}\text { Intermediate } \\
(\mathbf{n}=28)\end{array}$ & $\stackrel{\text { Low }}{(n=18)}$ \\
\hline 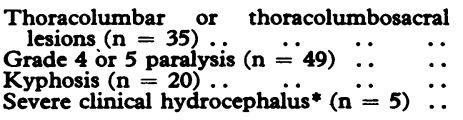 & $\begin{array}{r}27 \\
31 \\
19 \\
2\end{array}$ & $\begin{array}{r}7 \\
16 \\
1 \\
2\end{array}$ & $\begin{array}{l}1 \\
2 \\
0 \\
1\end{array}$ \\
\hline
\end{tabular}

* Severe clinical hydrocephalus as defined by Lorber indicates a head circumference at least $2 \mathrm{~cm}$ greater than the 90th centile using O'Neill's norms.

\section{References}

Brocklehurst, G., Gleave, J. R. W., and Lewin, W. S. (1967). British Medical Fournal, 1, 666 .

Egan, Dorothy F., Illingworth, R. S., and MacKeith, R. C. (1969). Developmental Screening 0-5 years. London, Heinemann.

mental Screening $0-5$ years. London, Heinemann.
Hamilton, W. J. (1966). Textbook of Anatomy. London, Macmillan. Hamilton, W. J. (1966). Textbook of Anatomy. London, Macmillan.

Lorber, J. (1971) Developmental Medicine and Child Neurology, 13, 279.

Lorber, J. (1972). Archives of Disease in Childhood, 47, 854.

O'Neill, Eileen M. (1961). Archives of Disease in Childhood, 36, 241

Porter, R. W. (1967). Developmental Medicine and Child Neurology, Suppl. No. 15 , p. 62 .

Sheridan, Mary D. (1960). Developmental Progress in Infants and Young Children. London, H.M.S.O.

Smith, E. Durham, and Smith, G. Keys. (1973). To be published.

Stark, G. D., and Drummond, Margaret, G. (1973). Archives of Disease in Childhood. In press.

\section{Early Results of Selective Treatment of Spina Bifida Cystica}

\section{J. LORBER}

British Medical fournal, 1973, 4, 201-204

\section{Summary}

The results of a policy of "selection" in treating infants with spina bifida cystica over 21 months are presented. Of 37 newborn infants referred on the first day of life 25 were not treated because of the severity of their condition, as defined by exact criteria. All died under 9 months of age. In contrast, only one treated infant died and the rest are either normal or moderately handicapped. Selection for treatment is offered as the best but not a good solution to an insoluble problem.

\section{Introduction}

Two major revolutions have occurred in the past 15 years in

\footnotetext{
Department of Child Health, University of Sheffield, Sheffield S10 2TH

J. LORBER, M.D., F.R.C.P., Reader in Child Health
}

the treatment of myelomeningocele. The first was the enthusiasm or moral compulsion to treat all infants, irrespective of the degree of their handicap-largely the result of the insistence of the Sheffield team (Sharrard et al., 1963; Zachary, 1968). The main reason for this enthusiasm was the introduction of the ventriculoatrial shunt in 1958. This procedure was able to control hydrocephalus effectively for the first time.

The second event was the disillusionment which occurred because the technical advances, especially the use of unidirectional valve systems to control the associated hydrocephalus, led to hopes that were unfortunately not fulfilled. Analysis of the results (Lorber, 1971; 1972 a) have shown that treating all infants still resulted in a high mortality rate in those cases severely affected at birth and yet led to the prolonged survival of many severely handicapped children, with gross paralysis, multiple deformities of the legs, fractures, kyphosis, scoliosis, incontinence of urine and faeces with frequent secondary effects of hydronephrosis, chronic pyelonephritis, and arterial hypertension. Hydrocephalus was usually well controlled with shunt therapy-in those who needed operation-but the complications of shunt therapy are exitremely common, requiring repeated operations. The mortality rate from these complications alone was $20 \%$ within seven years of the first shunt operation in a large group of 